
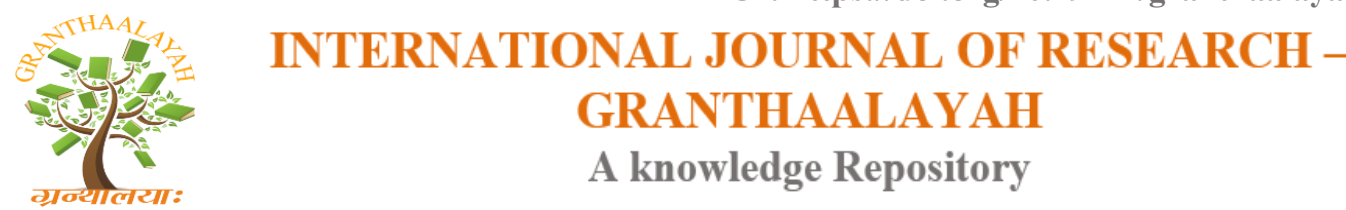

\title{
LINKING BALANCED SCORECARD MEASURES TO SMES' BUSINESS STRATEGY: ADDRESSING THE MODERATING ROLE OF FINANCIAL RESOURCES
}

\author{
Mahshid Lonbani ${ }^{1}$, Saudah Sofian ${ }^{* 2}$, Mas Bambang Baroto ${ }^{3}$ \\ ${ }^{1} \mathrm{Ph} . \mathrm{D}$ Candidate, Faculty of Management, Universiti Teknologi Malaysia, Skudai, 81310, Johor \\ Bahru, MALAYSIA \\ ${ }^{* 2}$ Associate Professor, Faculty of Management, Universiti Teknologi Malaysia, Skudai, 81310, \\ Johor Bahru, MALAYSIA \\ ${ }^{3}$ Associate Professor, International Business School, Universiti Teknologi Malaysia, Kuala \\ Lumpur, MALAYSIA
}

\begin{abstract}
Using financial and non-financial measures, the Balanced Scorecard (BSC) approach evaluates different aspects of firms' performance: financial, customer, learning and growth, and internal business processes. Resource flexibility and availability of financial resources are basically highlighted as separate antecedents of company's performance. Grounded on resource based view, the role of financial resources on business strategy has been addressed numerously in previous studies. However, there is limited study to evaluate the role of financial resources on relationship between business strategy and BSC performance measures. Especially there is no study addressing this issue according to the moderating role of financial resources among small and medium enterprises (SMEs). It is worth mentioning that such relationships and models can be more highlighted in a developing countries since financial resources has been debated to be weak in theses context. Grounded in contingency theory, an evaluation of the moderating role that financial resources plays in the relationship between SMEs' business strategy and balanced scorecard performance measures in SMEs points to the value of providing enough resources for SMEs. External fund providers such as banks and loan providers can help SMEs in this regard since firms could pass the way from business strategy to superior BSC performance measures more successfully.
\end{abstract}

Keywords:

Balanced Scorecard, Performance Measurement, Small and Medium Enterprises, Business Strategy.

Cite This Article: Mahshid Lonbani, Saudah Sofian, and Mas Bambang Baroto, "LINKING BALANCED SCORECARD MEASURES TO SMES' BUSINESS STRATEGY: ADDRESSING THE MODERATING ROLE OF FINANCIAL RESOURCES" International Journal of Research - Granthaalayah, Vol. 3, No. 12(2015): 92-99. 


\section{INTRODUCTION}

Firms' strategy can be explained as a way of pursuing different goals and objectives grounded on opportunities and threats in the environment as well as firm's capabilities and resources. An effective strategy can help organizations to sustain their competitive advantage which could subsequently lead to superior performance (Oosthuizen, 1997). However this can be accomplished only if the firm's internal and external conditions match appropriately with firm's strategy (Thompson and Strickland, 1996).

The link between strategy and performance among SMEs has been widely researched. It is widely assumed that there is a clear link between strategy, firm performance and competitive advantage to generate above-average returns. The positive effect of strategy on firm's performance has been highlighted by different scholars. For instance, according to Carraresi, Mamaqi, Albisu Aguado, and Banterle (2011) there are significant and positive direct relationships between firm strategic choices (innovation, product positioning and relationship development) and performance. Another study which was conducted by Lechner and Gudmundsson (2014) showed that there is a positive influences of both generic strategies on small firm's performance. Similarly, Singh and Mahmood (2014) conducted the study to find out whether there is a relationship between manufacturing strategy and export performance of SMEs in Malaysia. Based on the results, the scholars revealed that there is a significant and positive relationship between manufacturing strategy and export performance of SMEs. However the number of studies addressing the relationship between SMEs' strategy and BSC performance measures are very rare.

Performance measurements in organisations have generated much interest over the years in different business disciplines in different sectors. The developments in performance measurements have been strongly influenced by the increasing level of competition and the changing business environment (Johnson and Kaplan, 1987). Changes in the performance measurements have evolved and expanded for the past half century (Eccles, 1991; Kaplan, 1994).

Using traditional financial measures as one of the performance measurement system was criticized immensely in recent years. Specifically, many boundaries and difficulties related with traditional financial performance measurements were recognised in the literature. These boundaries were due to extreme concentration on the short-term by using the measures like incomes, without focusing on longer-term performance measures such as customer satisfaction and product or service quality. Usually the main focus on short-term financial accounting measures might no longer offer an acceptable information of well performance for business firms. Additionally, several scholars defined the most significant problems associated with oldstyle monetary performance measurements throughout the 1980s and early 1990s.

Drury (1990) believed that new performance measures are based on non-financial factors and give emphasis to factors such as flexibility, quality and delivery performance. In this regard, Bromwich and Bhimani (1994) believed that the significance of using non- financial data could not be overstated and that empirical evidence suggests a growing role for this type of information in enterprise management. Consequently, it can be said that financial measures are not sufficient 
for the purpose of deciding in the modern enterprise, and the collection of relevant performance measures, both financial and non-financial measures should be considered. Key multifaceted/multivariate examples in this regard include Fitzgerald, Johnston, Brignall, Silvestro, and Voss (1991) "results and determinants" framework; most notably, Kaplan and Norton (1992) "balanced scorecard" approach; Lynch and Cross (1995) "performance pyramid" and the performance prism Neely, Adams, and Kennerley (2002). The focus of this study is on balanced scorecard approach with combines both financial and non-financial measurements.

\section{USE OF BALANCED SCORECARD AMONG SMES}

Regarding the essentiality of using key non-financial performance measures and integrate financial and non-financial measures, Kaplan and Norton (1992) developed the BSC as a multidimensional performance measures to help mangers have a complete view of the organization, and providing them consistent feedback for management controlling goals and evaluating the performance. This approach contains two kinds of performance measures. The first one refers to the financial measures for describing the previous actions. The second one refers to the non-financial measures regarding the customer satisfaction, internal business process, and learning and growth activities as drivers of future financial performance.

There are a large body of studies which address the use of BSC in large organizations; however, the available literature regarding the use of BSC in small firms is very few. Andersen, Cobbold, and Lawrie (2001) stated that reported lack of related literature about the BSC implementation among SMEs must not be considered as an indication that the BSC application is just suitable for large companies.

Though scarcity, available literature clarified the applicability of using this performance measurement system in SMEs. There are many studies which highlighted the feasibility of using BSC in these contexts (Hongmei and Yujun, 2010; Tennant and Tanoren, 2005; Andersen, Cobbold, and Lawrie, 2001; Gumbus and Lussier, 2006). There are different reasons why BSC can be applied in these specific groups of companies:

- Helping SMEs to plan for short as well as long term objectives(Von Bergen and Benco, 2004)

- $\quad$ Supporting SMEs to achieve their goals and being innovative (Zinger,2002)

- Making performance management much easier (Gomes and Lírio, 2014)

Although SMEs have used BSC only for a short period of time, they have applied and used the first two generations of BSC. Meaning that BSC has been used as a tool for measuring performance and also a strategic management system (Garengo, Biazzo, and Bititci, 2005; Fernandes, Raja, and Whalley, 2006; Gumbus and Lussier, 2006; Henschel, 2006). Therefore, this highlights the quick implementation of BSC generations among SMEs. The use of BSC as a performance measurement system can be more highlighted for SMEs since they not only can focus on financial performance indicators but also on non-financial ones which could improve their competitive advantage in a rapidly changing market environment. 


\section{CONTINGENCY THEORY : BUSINESS STRATEGY AND PERFORMANCE}

The focus of contingency theorists has been on contingencies based on the internal and external environment. Strategy researchers have long highlighted that firms should grounded their selected strategy not only in internal capabilities and resources but also in external environment. In this case they could achieve superior performance (Zou and Cavusgil, 1996). The role of financial resources as a component of internal environment and contingency factor, affecting the SMEs' business strategy-BSC performance measurement relationship has not received scholarly attention.

Contingency theories demonstrated the significance of alignment or fit amongst various constructs related to the organizations and explain the way the relationship between performance and measures of strategy can be moderated by different environmental factors. (e.g Lumpkin and Dess, 2001; Venkatraman \& Prescott, 1990). The rationale is simply that were firms deliver goods that customers value more highly that comparable offerings of rivals, then greater financial and personal rewards will accrue to the organization and its employees. Conversely, where performance is not satisfactory and poor, firms need to reformulate the selected strategy based on environmental context.

The capability of an organisation for surviving and being successful is affected by different factors. Some of those factors can and some of them cannot be controlled. As a result, an organisation's performance is a function of the uncontrollable and controllable variables. One of these factors can be related to one the most important elements of internal environment which is firm's financial resources.

\section{FINANCIAL CAPACITY AVAILABILITY AMONG SMES}

SMEs possess more constrained resources compared to larger ones (Bianchi and Noci, 1998) although they also have essentially different resources that are usable in extremely different ways. Due to insufficiency of resources the smaller companies are more responsive to pressures of stakeholders compared to larger ones.

Previous scholars have highlighted different internal factors affecting SMEs, however two parameters financial resources and management, were common among these studies. According to Kadocsa and Francsovics (2011), financial resources is the second most important factor (after having a good relationships with customers) affecting the SMEs' operation in Budapest. Olawale and Garwe (2010) also investigated the internal and external environmental obstacles to the growth of new SMEs in South Africa, the results showed that financial and management are two internal factors which were considered as the obstacles for growth. The scholars referred to finance as the most important parameter compared to the other factors. According to Chittithaworn, Islam, Keawchana, and Yusuf, (2011) SMEs characteristics, the way of doing business, resources and finance were main internal factors affecting SMEs' success in Thailand. Similarly Kalpande, Gupta, and Dandekar, (2010) highlighted the role of financial stringency and technological obsolescence as the main threat for Indian SMEs. According to Saleh and Ndubisi (2006) Malaysian SMEs have difficulties in obtaining funds from financial institutions and the government. Access to finance includes the difficulties in accessing loans and other 
forms of financial assistance. Aragón-Sánchez and Sánchez-Marín (2005) highlighted the influence of financial resources through the evaluation of the factors which could tension SMEs. There are many factors that compel the firms to face the challenges to improve their competitiveness, which include the economy internationalization, greater competition among companies, the uncertain and frequent changes, the growing utilization of information technologies, and the requirement for constant innovations. According to these scholars for SMEs, the above mentioned difficulties are greater since their economies of their resources are less than those of the larger companies. As a result, according to the previously conducted studies, this study focuses mainly on financial resources as an important internal factor that has effect on strategy-BSC performance measures relationship.

\section{CONCEPTUAL FRAMEWORK AND HYPOTHESIS DEVELOPMENT}

The conceptual framework which was modelled in this study examines the interaction between business strategy and balanced Scorecard performance measures among SMEs. In addition it was hypothesised that the effect of firms' strategy on performance measurement based on BSC approach will vary depending on availability of financial resources. As demonstrated in the conceptual framework in Figure 1, the relationship between SMEs' business strategy, BSC performance measurements and financial resources can be hypothesized as follows:

- SMEs' business strategy can positively influence BSC performance measures

- Availability of financial resources moderate the relationship between SMEs' business strategy and BSC performance measures

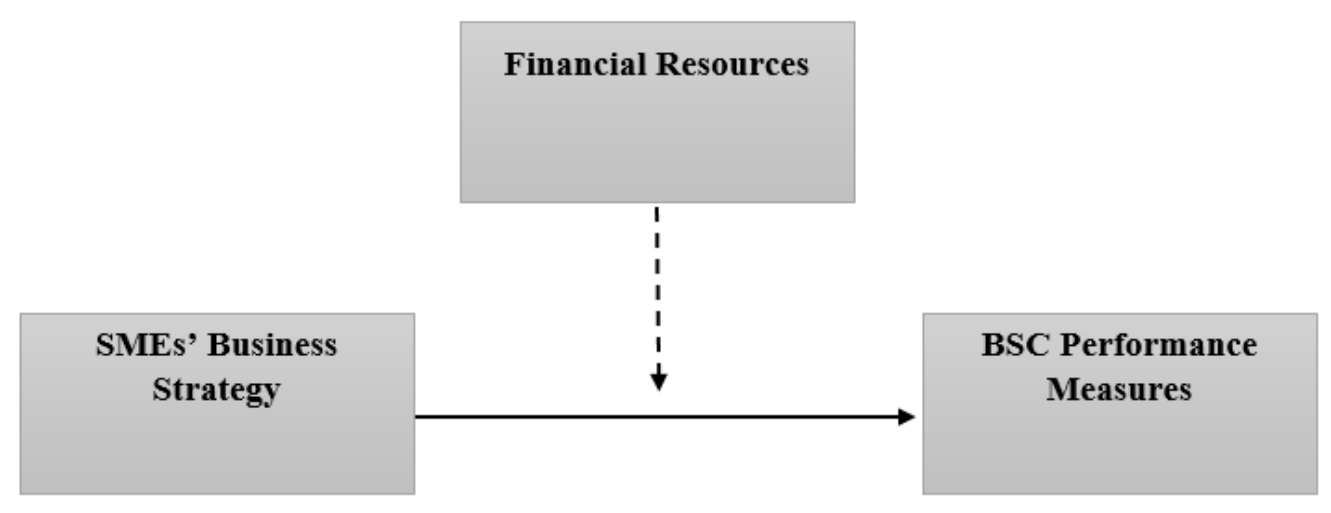

Figure 1: The Impact of Financial Resources on the Relationship Between Business Strategy and BSC performance Measures in an SME-A Conceptual Framework

\section{CONCLUSION AND RECOMMENDATION}

SMEs are considered as a backbone of the economy. The significance of their continues performance improvement in global economy is deniable. The SMEs performance improvement 
can be accomplished by using BSC. However availability of financial resources can play a great role in this regard. Because the BSC process is comprehensive, SMEs which use this performance measurement system should have adequate resources especially financial resources to be successful. Therefore it is expected that financially rich firms can pass the way from business strategy to BSC performance measurement more successfully compared to financially poor SMEs. Lack of financial resources can prevent SMEs to adopt a broad performance measurement system such as balanced scorecard. BSC is a luxury system for SMEs. The cost of this system can be considered as a fundamental concern for SME mangers. Nowadays, information system which could provide needed data for measures has been used in most SMEs; however, the cost of purchasing and implementing BSC can still be an issue for leaders of SMEs. Nevertheless this cannot be an obstacle for SME leaders to use BSC approach to evaluate their performance. Finally it is of great importance to support SMEs financially so that they could implement a compressive tools such as BSC to evaluate and improve their performance.

\section{REFERENCES}

[1] Aragón-Sánchez, A., and Sánchez-Marín, G. (2005). Strategic Orientation, Management Characteristics, and Performance: A study of Spanish SMEs. Journal of Small Business Management. 43(3): 287-308.

[2] Andersen, H., Cobbold, I., and Lawrie, G. (2001). Balanced Scorecard Implementation in SMEs: Reflection on Literature and Practice. 4th SME International Conference, Denmark, 14-16 May

[3] Bianchi, R., and Noci, G. (1998). Greening" SMEs' Competitiveness. Small Business Economics. 11(3): 269-281.

[4] Bromwich, M., and Bhimani, A. (1994). Management Accounting: Pathways to Progress. CIMA Publishing Imprint.

[5] Carraresi, L., Mamaqi, X., Albisu Aguado, L. M., \& Banterle, A. (2011). The relationship Between Strategic Choices and Performance in Italian Food SMEs: a Resource-based Approach.

[6] Chittithaworn, C., Islam, M.A., Keawchana, T., and Yusuf, D.H.M. (2011). Factors Affecting Business Success of Small \& Medium Enterprises (SMEs) in Thailand. Asian Social Science. 7(5): 180-190

[7] Drury, C. (1990). Cost Control and Performance Measurement in an AMT Environment. Management Accounting. 68(10): 40-44.

[8] Eccles, R. (1991). The Performance Measurement Manifesto. Harvard Business Review, January-February, 131-137.

[9] Fernandes, K.J., Raja, V., and Whalley, A. (2006). Lessons from Implementing the Balanced Scorecard in a Small and Medium Size Manufacturing Organization, Technovation. 26(5): 623-634.

[10] Fitzgerald, L., Johnston, R., Brignall, T.J., Silvestro, R. and Voss, C. (1991). Performance Measurement in Service Businesses. C.I.M.A. London.

[11] Garengo, P., Biazzo, S., and Bititci, U.S. (2005). Performance Measurement Systems in SMEs: a Review for a Research Agenda. International journal of management reviews. 7(1): 25-47. 
[12] Gomes, R. C., \& Lírio, V. S. (2014). Strategic Planning in Brazilian Small-Scale Municipalities: Is the Balanced Scorecard a Feasible Tool? Revista de Administração da UFSM, 7(1): 8-21.

[13] Gumbus, A., and Lussier, R.N. (2006). Entrepreneurs Use a Balanced Scorecard to Translate Strategy into Performance Measures. Journal of Small Business management. (44)3: 407-425.

[14] Henschel, T. (2006). Risk Management Practices in German SMEs: An Empirical Investigation. International Journal of Entrepreneurship and Small Business. 3(5): 554571.

[15] Hongmei, C., and Yujun, M. (2010). Knowledge Management for SMEs Based on the Balanced Scorecard. In Management and Service Science (MASS), 2010 International Conference on, pp. 1-4

[16] Johnson, H.T., and Kaplan, R.S. (1987). Relevante Lost-The Rise and Fall of Management Accounting. Boston, MA: Harvard Business School Press.

[17] Kalpande, S.D., Gupta, R.C., and Dandekar, M.D. (2010). A SWOT Analysis of Small and Medium Scale Enterprises Implementing Total Quality Management. International Journal of Business Management and Social Sciences. 1(1): 59-64.

[18] Kaplan, R. (1984). The Evolution of Management Accounting. The Accounting Review. 59(3): 390-418.

[19] Kaplan, R. and Norton, D. (1992). The Balanced Scorecard - Measures that Drive Performance. Harvard Business Review. 70(1): 71-8.

[20] Kadocsa, G., and Francsovics, A. (2011). Macro and Micro Economic Factors of Small Enterprise Competitiveness. Acta Polytechnica Hungarica. 8(1): 23-40.

[21] Lechner, C., \& Gudmundsson, S. V. (2014). Entrepreneurial Orientation, Firm Strategy and Small Firm Performance. International Small Business Journal, 32(1), 36-60.

[22] Lumpkin, G.T. and Dess, G.G. (2001). Linking two Dimensions of Entrepreneurial Orientation to Firm Performance: The Moderating Role of Environment and Industry Life Cycle. Journal of Business Venturing. 16(5): 429-451.

[23] Lynch, R. and Cross, K. (1995). Measure up. How to Measure Corporate Pperformance. USA: Blackwell.

[24] Neely, A.D., Adams, C., and Kennerley, M. (2002). The Performance Prism: The Scorecard for Measuring and Managing Business Success. London: Prentice Hall Financial Times.

[25] Olawale, F., and Garwe, D. (2010). Obstacles to the Growth of New SMEs in South Africa: A principal Component Analysis Approach. African Journal of Business Management. 4(5): 729-738.

[26] Oosthuizen, H. (1997), “An Evaluation of the Relevance of the Miles and Snow Strategic Typology under Present-day Conditions of Major Environmental Uncertainty - the Emperor's New Clothes or a Paradigm Shift?", South African Journal of Business Management, Vol. 28 No. 2, pp. 63-72.

[27] Saleh, A.S., and Ndubisi, N.O. (2006). SME Development in Malaysia: Domestic and Global Challenges. Faculty of Commerce-Economics Working Papers. 139. University of Wollongong

[28] Singh, H., and Mahmood, R. (2014). Manufacturing Strategy and Export Performance of Small and Medium Enterprises in Malaysia: Moderating Role of External Environment. International Journal of Business \& Commerce. 3(5): 37-52 
[29] Tennant, C., and Tanoren, M. (2005). Performance Management in SMEs: a Balanced Scorecard Perspective. International Journal of Business Performance Management. 7(2): 123-143.

[30] Thompson, A.A. Jr and Strickland, A.J. (1996), Strategic Management, 9th ed., Irwin, Chicago, IL.

[31] Venkatraman, N., and Prescott, R. (1990). Environment-strategy coalignment: An Empirical Test of Its Performance Implications. Strategic Management Journal. 11(1): 123.

[32] Von Bergen, C.W., and Benco, D.C. (2004). A Balanced Scorecard for Small Business. Proceedings of the United States Association for Small Business and Entrepreneurship Conference. Dallas, Texas, pp. 15-18. January 15-18.

[33] Zinger, J. T. (2002). The balanced Scorecard and Small Business: A Stages of Development Perspective. Paper Presented at the International Council for Small Business, 47th World Conference, San Juan, Puerto Rico, pp.1-22. 19 Jun

[34] Zou, S. and Cavusgil, S.T. (1996), "Global Strategy: A Review and an Integrated Conceptual Framework”, European Journal of Marketing, Vol. 30 No. 1, pp. 52-69. 